\title{
Supply Chain Risk Management using Expert Systems
}

\author{
Mehrdokht Soleymani* and Maryam Oveysi Nejad \\ Iran Science and Technology University, Iran \\ Received 12 May 2018, Accepted 14 July 2018, Available online 16 July 2018, Vol.8, No.4 (July/Aug 2018)
}

\begin{abstract}
Supply chain risk management (SCRM) is a new concept in logistic science. SCRM becomes more important because of the increasing global risks in industries. This paper reviews important literature about supply chain risk management using expert systems. To this goal, we should introduce methods of identifying risks and their impacts on the supply chain performance, in qualitative and quantitative manners. In the qualitative methods, questionnaires are used and the quantitative methods are based on the probability theory and Fuzzy logics, expert systems, especially. The results show that expert systems can identify supply chain risks and therefore they help to leaders decision making process.
\end{abstract}

Keywords: Supply chain risk, Expert system, Fuzzy logic, Risk identification

\section{Introduction}

\subsection{Supply Chain Management}

Today, the business environment in different field and industries is saturated and there is no chance for an organization to be successful without effective supply chain management system. The supply chain is an interconnected ring of factors that interactions between them cause to produce valuable goods or services.

Supply chain management is the integrated management of information, products and cash flows, somehow that the maximum value of the organization and costumers earned. The historical background of this concept came back to 1960 decade. In those years, businesses used standards to enhance the quality of their products and services, systematically. In 1980s, the costumers in the world were raised in some developing industries. This causes to businesses to have more efficient customer satisfaction approaches, through supply chain agility methods. In two decades later, supply chain management using information technology became a hot and challenging field of research. It is obvious that a simple supply chain management model includes planning, sourcing, producing, delivery and after sale services steps.

*Corresponding author's ORCID ID: 0000-0000-0000-0000 DOI: https://doi.org/10.14741/ijcet/v.8.4.12

\subsection{Supply Chain Risks}

Globalization and enterprise development have causes to increase the supply chain risks, drastically. Risk is the potential of gaining or losing something of value. Values (such as physical health, social status, emotional well-being, or financial wealth) can be gained or lost when taking risk resulting from a given action or inaction, foreseen or unforeseen (planned or not planned). Risk can also be defined as the intentional interaction with uncertainty. Uncertainty is a potential, unpredictable, and uncontrollable outcome; risk is a consequence of action taken in spite of uncertainty (Cline, 2016). On the other hand, supply chain risk is a potential event that makes disorder in normal information, product and cash flows (Juttner, 2006).

Hesami and Savoji studied the supply chain risks and their impacts on the enterprise's performance. They proposed a model to evaluate the identified risk intensities, relative to each other. Their results showed that the most important supply chain risks are environmental, financial, strategy, informational and equipment risk, respectively according to their impact intensities.

Talebi and Iron identified and analyzed the supply chain risks in automotive industry using the analytic network process (ANP). They concluded that the supply chain risks can be used during supplier selection and risk control. 
In another interesting study, all the important methods of identifying, prioritizing and managing the supply chain risks were reviewed (OuTang, 2011). Their results show that the existing models are not taking into account the informational risks. Also, we need to work with big data to do some statistical analysis of an efficient supply chain risk management.

Expert systems are software applications that simulate thinking process of an expert in a specific field. This idea introduced by Hayes Roth et al. for the first time at 1980s. They proposed using artificial intelligence and knowledge engineering to simulate the expert's thinking process. Also, they developed a comparative analysis to identify strength and weakness consist of eight different techniques.

\section{Supply Chain Risk Management using Expert Systems}

Yazdani et al. propose a decision support model for selecting logistics providers based on the quality function deployment (QFD) and the technique for order preference by the similarity to ideal solution (TOPSIS) for agricultural supply chain in France. The research provides a platform for group decision making to facilitate decision process and check the consistency of the outcomes.

The proposed model looks at the decision problem from two points of view considering both technical and customer perspectives. The main customer criteria are confidence in a safe and durable product, emission of pollutants and hazardous materials, social responsibility, etc. The main technical factors are financial stability, quality, delivery condition, services, etc. based on the literature review. The second stage in the adopted methodology is the combination of quality function deployment and the technique for order preference by similarity to ideal solution to effectively analyze the decision problem. In the final, they structure a group decision system called GRoUp System (GRUS) to facilitate the decision making process.

They designed a group decision making system to interface decision makers and customer values in order to aid agricultural partners and investors in the selection of third party logistic providers.

Moreover, they have figured out a decision support system under fuzzy linguistic variables is able to assist agricultural parties in uncertain situations. This integrated and efficient decision support system enhances quality and reliability of the decision system. Aqlan presents a software application framework for rapid risk assessment (RRA) in integrated supply chains. The proposed framework combines qualitative and quantitative methods to assess and prioritize the risks. Risk is calculated for each agent in the supply chain and are then aggregated per product type. The proposed RRA tool was tested in a manufacturing environment to assess the validity of the proposed framework. The following equation is used to aggregate the risk likelihood:

$$
P_{n}=1-\prod_{i=1}^{M}\left(1-p_{i}\right)
$$

Where $P n$ is the aggregated probability of occurrence of risk for agent $\mathrm{n}$ and $p i$ is the probability of occurrence of risk factor i. $\mathrm{M}$ is the number of risk factors associated with the risk agent $n$. The aggregated impact of the risk is then calculated as:

$L_{n}=\frac{\sum_{i=1}^{M} p_{i} \times L_{i}}{\sum_{i=1}^{M} p_{i}}$

Where $L n$ is the aggregated likelihood of the risk for agent $\mathrm{n}$ and $l i$ is the resulting impact factor $\mathrm{i} . \mathrm{M}$ is the number of risk factors associated with the agent $n$. The two aggregated parameters, risk likelihood and impact, are used to calculate the risk score for the agent using the fuzzy inference system.

An illustration of the fuzzy inference system is shown in Figure 1. The membership function for the linguistic variables on the risk likelihood is shown in Figure 2.

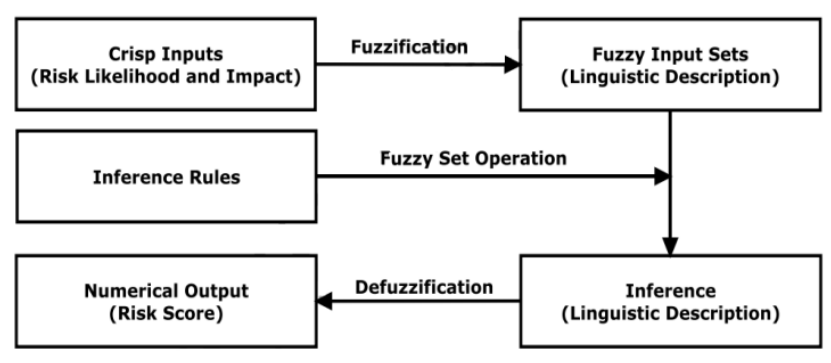

Figure 1: An illustration of the fuzzy logic system (Faisal Aqlan, 2015)

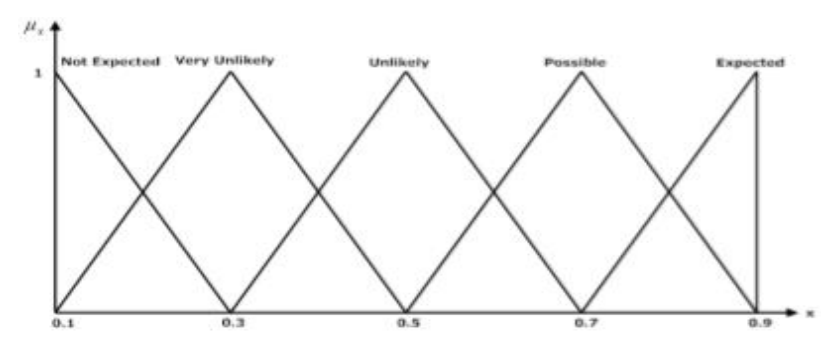

Figure 2: Membership function of the likelihood linguistic variable (Alexander König, 2016) 


\begin{tabular}{|l|c|l|c|c|c|c|c|c|}
\hline County & Country Risk & Supplier & Supplier Risk & Agg. Suplier Risk & Part & Part Risk & Agg. Part Risk \\
\hline Country 1 & 0.23 & Supplier 1 & 0.51 & 0.42 & Manufacturer & Manufacturer Risk \\
\hline Country 3 & 0.31 & Supplier 3 & 0.32 & 0.31 & & & \\
\hline
\end{tabular}

Figure 3: Risk report for Product A (Alexander König, 2016)

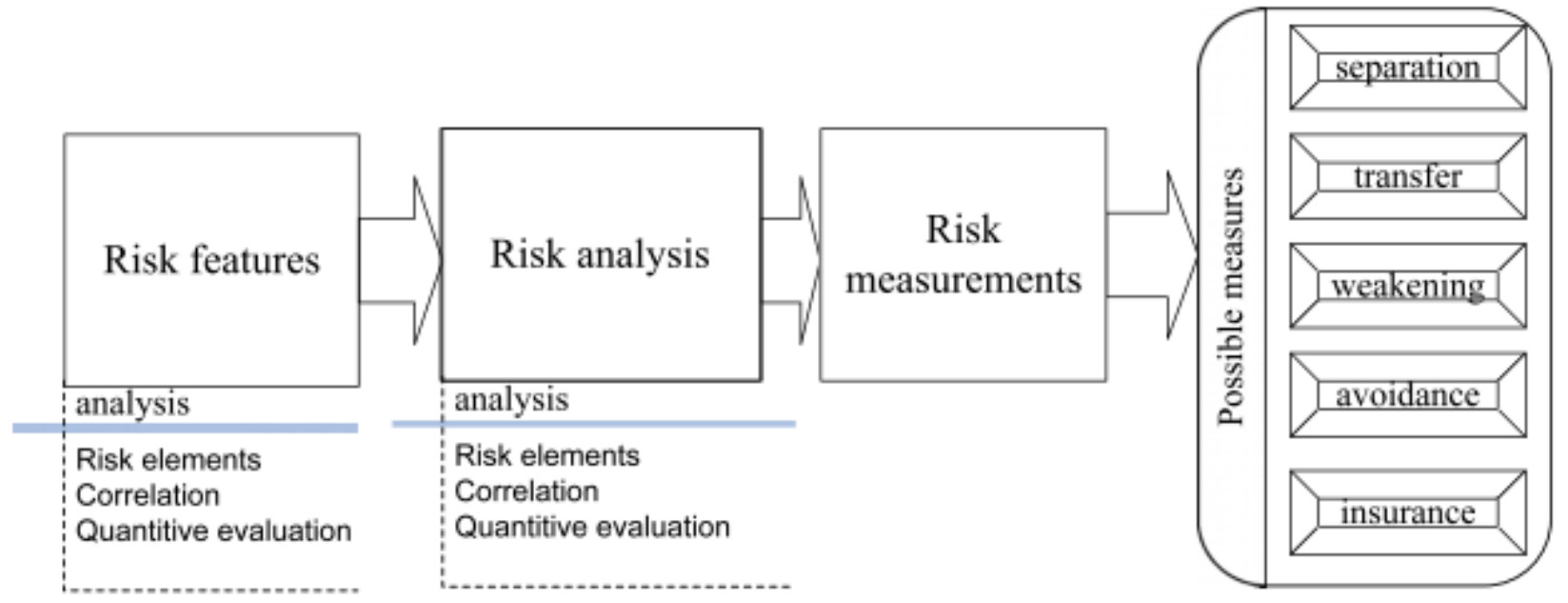

Figure 4: Basic decision-making model for SC risk management (De Xia, 2011)

To assess the total risk for each agent of the supply chain, the risk priority matrix is proposed. The risk priority matrix is used to calculate the overall risk for each supply chain agent and the overall score for each risk type. The software tool was developed using VBA and SQL programming languages. Also, The Agent Identification module identifies the main agents in the supply chain, mainly based on SCOR model. Main agents in the supply chain include: environment, suppliers, supplier hubs, manufacturers, distribution centers, and customers. Depending on the supply chain structure, risk can transfer from one agent to another and affect the whole supply chain.

This software used questionnaire data to simulate the expert's thinking process. For each risk factor, the respondents are asked to estimate the probability of the risk with a number between 0 and 1 and the estimated impact (also with a value between 0 and 1 ). The risk report generated by the RRA software for a specific product is shown in Figure 3. The assessment obtained by the proposed framework agrees with what the risk management experts think about the risk levels in the company.
Xia and Chen proposed a decision-making model based on the internal triggering and interactive mechanisms in an SC risk system, which takes into account dual cycles, the operational process cycle (OPC) and the product life cycle (PLC). They explored the interrelationship among the two cycles, SC organizational performance factors (OPF) and available risk operational practice (ROP), as well as the risk managerial elements in OPC and PLC. In particular, three types of relationship, bilateral, unilateral and inter-circulative ones, are analyzed and verified. They built this dynamic relation into SC risk managerial logic and design a corresponding decision making path. Based on the analytic network process (ANP), a methodology is designed for an optimal selection of risk management methods and tools. A numerical example is provided as an operational guideline for how to apply it to tailor operational tactics in SC risk management. To deal with these various risks with different attributes, practitioners may have many choices, such as separation, transfer, weakening, avoidance and insurance (see Fig. 4). 


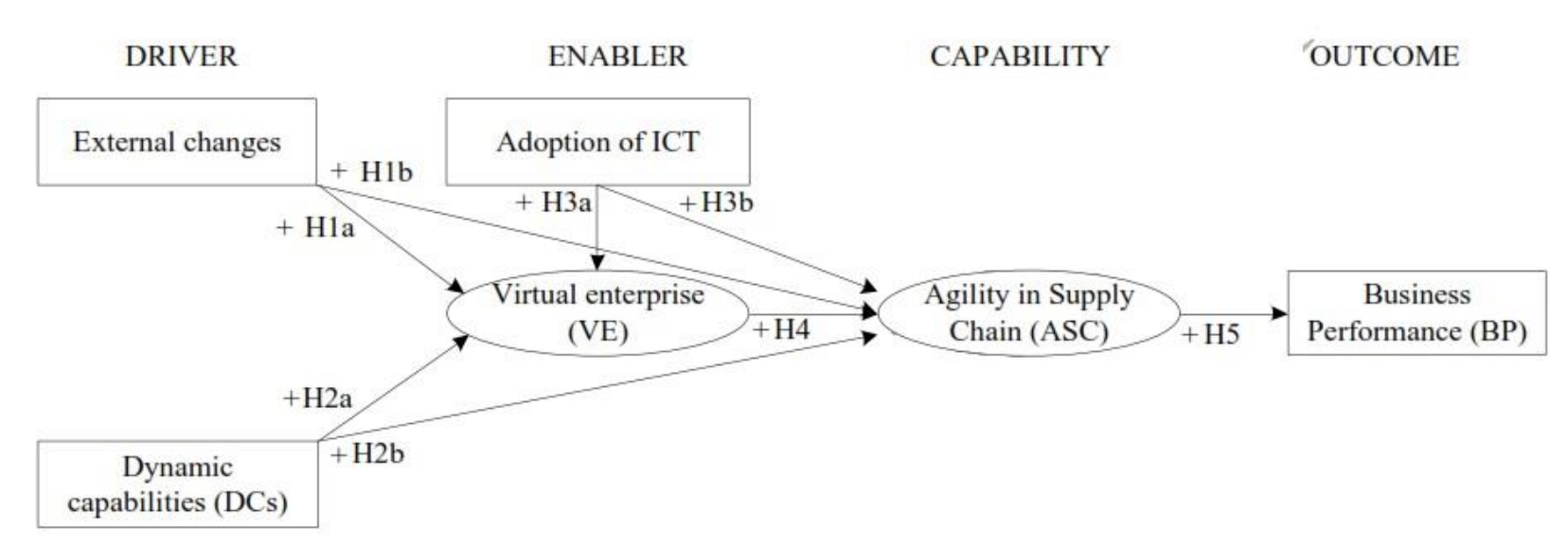

Figure 5: Proposed conceptual model (Ariunbayar Samdantsoodol, 2017)

The results verify that this strategic decision model is a feasible access to the suitable risk operational tactics for practitioners. SC risk factors inter-relations could be predictable using such a model.

Vlahakis et al. studied enabling situation awareness with supply chain management. In their approach, situation awareness is facilitated by providing the capability to detect situations, which are represented as correlations between simple events, complex events and supply chain objects (e.g., suppliers, 3PL companies, retailers and material resources). They introduce a two-phase event correlation method which first correlates simple events into complex events and then events with supply chain objects. Their framework by incorporating algorithms that can predict emerging situations, which will enhance the capabilities of supply chain managers to plan and execute processes proactively.

Samdantsoodol et al. proposed a model for predicting the relationships between virtual enterprises and agility in supply chains. To clarify the relationships between factors a structural equation model (SEM) is adopted to examine the model fit according to the measurement variables and supporting hypotheses. Their results provide rich empirical evidence of the beneficial impact of VEs on ASCs, and theoretical and managerial insights that can be used to strengthen the drivers, enablers and capabilities to enhance the effectiveness of VE collaboration in ASCs in a global and dynamic context. Also, the analysis results can aid a decision maker, which ones of the factors are the important ones that he or she should devote more resources and efforts on.

To analyze the aggregated research schema, empirically, a novel complex conceptual model shown in Figure 5 is proposed. Their purpose is to investigate how drivers and enablers cause enterprises to join in VE and achieve in agility, how VE formation impacts on ASC based on previous partnering collaboration, and how achieved agility through strategies joining in VE causes BP.

Azadeh and Alam [13] performed a flexible deterministic, stochastic and fuzzy data envelopment analysis approach for supply chain risk and vendor selection problem. They presented a decision making scheme for choosing the appropriate method for supplier selection under certainty, uncertainty and probabilistic conditions. They investigated three methods for supplier selection. These methods are, Data Envelopment Analysis (DEA), Fuzzy Data Envelopment Analysis (FDEA), and Chance Constraint Data Envelopment Analysis (CCDEA). Results from three models are compared. Their decision making scheme allows decision makers to perform analysis, among input factors which are expected costs, quality of acceptance levels, and on-time delivery.

Moeinzadeh and Hajfathaliha proposed a combined fuzzy decision making approach to supply chain risk assessment. They aimed to reinforce SC risk management by proposing an integrated approach. SC risks are identified and a risk index classification structure is created. Then they developed a SC risk assessment approach based on the analytic network process (ANP) and the VIKOR methods under the fuzzy environment where the vagueness and subjectivity are handled with linguistic terms parameterized by triangular fuzzy numbers.

The risk drivers and their impacts are categorized in Table 1 and any risk impacts are listed, too. As one could observe, the most risks are on the supply side. Also, rigorous supply chain risk management is a cyclic process encompassing six phases (Figure 6). They detected 29 risk factors in a supply chain. Then they used Fuzzy ANP (FANP) method. The five most important risk classes are: 
Table 1 Categories of supply chain risks from the literature (P. Moeinzadeh, 2009)

\begin{tabular}{|c|c|c|}
\hline Risk category & Risk driver & Risk impact \\
\hline $\begin{array}{l}\text { Plan and control } \\
\text { risk }\end{array}$ & $\begin{array}{l}\text { - Applied methods, concepts and tools } \\
\text { - IT systems (breakdown, introduction or change of IT } \\
\text { systems, virus damage, change of interfaces, data loss) }\end{array}$ & $\begin{array}{l}\text { - Opportunity costs } \\
\text { - Cost of capital } \\
\text { - Logistics costs }\end{array}$ \\
\hline Supply risk & $\begin{array}{l}\text { - Quality of material } \\
\text { - Suppliers (failure, single sourcing, adherence to } \\
\text { delivery dates) } \\
\text { - Supplier dependence } \\
\text { - Global sourcing } \\
\text { - Supplier concentration } \\
\text { - Supply market } \\
\text { - Damage to cargo } \\
\text { - Monopoly situations (single sourcing) } \\
\text { - New strategic alignment of suppliers } \\
\text { - Illiquidity and insolvency of suppliers }\end{array}$ & $\begin{array}{l}\text { - Production stop } \\
\text { - Replacement } \\
\text { purchase costs } \\
\text { - Supply interruptions }\end{array}$ \\
\hline Process risk & $\begin{array}{l}\text { - Lead times } \\
\text { - Capacity bottleneck } \\
\text { - Output } \\
\text { - Quality } \\
\text { - Machine damage } \\
\text { - Human error } \\
\text { - Faulty planning } \\
\text { - Trouble with third-party logistics provider } \\
\text { - Major technological change }\end{array}$ & $\begin{array}{l}\text { - Supply difficulties } \\
\text { - Repair costs }\end{array}$ \\
\hline Demand risk & $\begin{array}{l}\text { - Demand fluctuations } \\
\text { - Changes in preferences } \\
\text { - Cancellations } \\
\text { - Planning and communication flaws in sales } \\
\text { department } \\
\text { - Inflexibility }\end{array}$ & $\begin{array}{l}\text { - Supply difficulties } \\
\text { - Safety stock } \\
\text { (Bullwhip effect) }\end{array}$ \\
\hline $\begin{array}{l}\text { Environmental } \\
\text { risk }\end{array}$ & $\begin{array}{l}\text { - Natural disasters (fire, earthquake, flood, rock fall, } \\
\text { landslide, avalanche, etc.) } \\
\text { - Weather (iciness, storm, heat) } \\
\text { - Political instability (strike, taxes, war, terrorist attacks, } \\
\text { embargo, political labor conflicts, industrial disputes) } \\
\text { - Import or export controls } \\
\text { - Social and cultural grievances } \\
\text { - Crime } \\
\text { - Price and currency risks/inflation }\end{array}$ & $\begin{array}{l}\text { - Opportunity costs } \\
\text { - Replacement costs }\end{array}$ \\
\hline
\end{tabular}

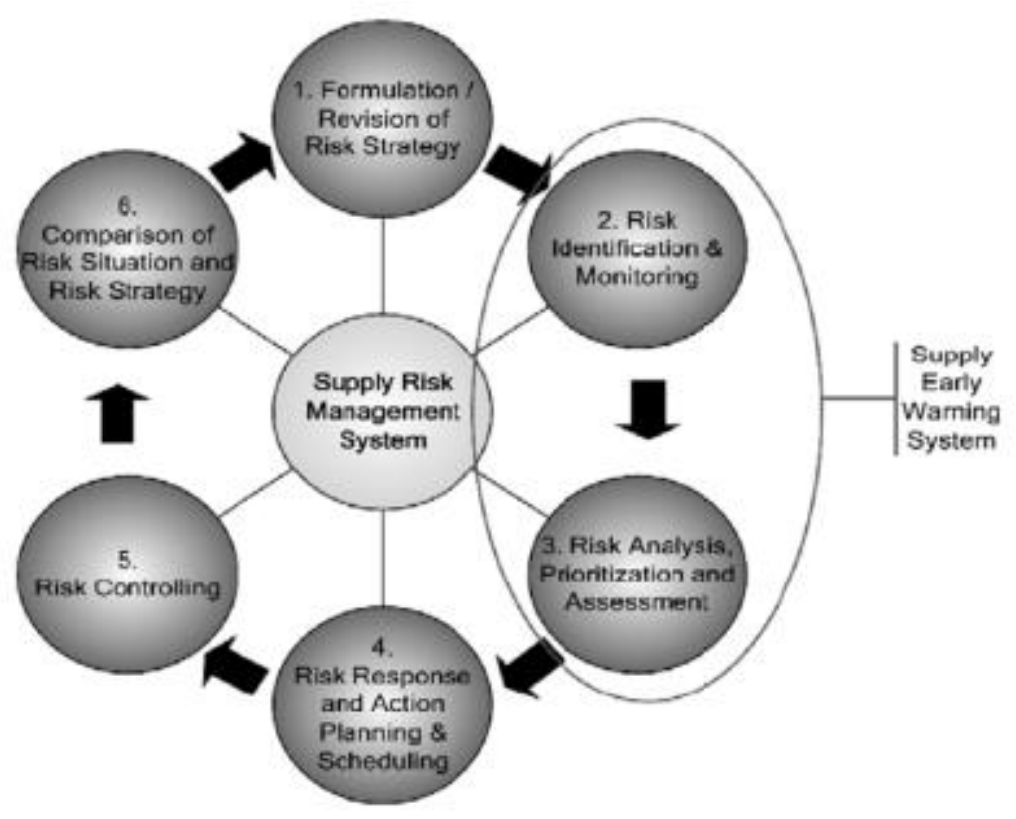

Figure 6: Supply Chain Risk Management System 
1) Plan and control risks

2) Supply risks

3) Process risks

4) Demand risk

5) Environmental risks

Also, the order of relative importance of the five supply chain risk categories is "Plan and control risk, "Process risk, "Demand risk, "Supply risk and "Environmental risk. The top five priorities of the risks are "Applied methods, concepts and tools, "Capacity bottleneck, "Faulty planning, "Quality and "Trouble with thirdparty logistics provider, respectively.

\section{Conclusion}

The ever-increased development of the modern enterprises and the globalization cause to enhanced supply chain risks, drastically. In this theme, we need to identify, prioritize and manage the supply chain risks. Expert systems could be used in supply chain risks management, through the simulation of the experts thinking process. This paper focuses on review of important literature on the expert systems using in the supply chain risk management. The results show that expert systems based on fuzzy logic results in efficient supply chain risk identification, in top five risk factors classes: Planning risks, supply risks, process risks, demand risks and environmental risks, can help to leaders decision making.

\section{References}

Cline, Preston B. (3 March 2015). The Merging of Risk Analysis and Adventure Education (PDF). Wilderness Risk Management. 5 (1): 43-45. Retrieved 12 December2016.

Juttner, U. (2005) Supply chain risk management: Understanding the business requirements from a practitioner perspective. International Journal of Logistics Management, 16.

Hesam, Zand Hesami and Ava, Savoji, Risk Management in Supply Chain Menegement, Development and Transformation Management Quarterly, No. 9, 2013, pp. 37-44 (in Persian).
Davood, Talebi and Fatemeh, Iron, Supply Chain Risk Identification and Supply Selection using ANP (Case Study: Aotumotive Industry), Industrial Management Vision, No. 17, 2016. pp. 13-43 (in Persian).

OuTang, Ou and Nurmaya M., Identifying risk issues and research advancements in supply chain risk management, International Journal of Production Economics, Volume 133, Issue 1, September 2011, Pages 25-34.

Hayes-Roth, F. ; Waterman, D. ; Lenat, D., Building expert systems, Addison-Wesley, Reading, MA, 1984.

Morteza Yazdani, Pascale Zarate , Adama Coulibaly , Edmundas Kazimieras Zavadskas, A group decision making support system in logistics and supply chain management, Expert Systems With Applications, DOI:10.1016/j.eswa.2017.07.014, 2017.

Faisal Aqlan , A Software Application for Rapid Risk Assessment in Integrated Supply Chains, Expert Systems With Applications (2015), doi 10.1016/j.eswa.2015.08.028

Alexander König \& Stefan Spinler, The effect of logistics outsourcing on the supply chain vulnerability of shippers: Development of a conceptual risk management framework, The International Journal of Logistics Management, VOLUME 27, ISSUE 1, 2016.

De Xia, Bo Chen, comprehensive decision-making model for risk management of supply chain, Expert Systems with Applications 38 (2011) 4957-4966.

George Vlahakis, Dimitris Apostolou and Evi Kopanaki, Enabling Situation Awareness with Supply Chain Event Management, Expert Systems With Applications, 2017, DOI: 10.1016/j.eswa.2017.10.013.

Ariunbayar Samdantsoodol, Shuang Cang, Hongnian Yu, Alan Eardley, Asralt Buyantsogt, Predicting the relationships between virtual enterprises and agility in supply chains, Expert Systems With Applications (2017), doi:10.1016/j.eswa.2017.04.037.

A. Azadeh, S.M. Alem, A flexible deterministic, stochastic and fuzzy Data Envelopment Analysis approach for supply chain risk and vendor selection problem: Simulation analysis, Expert Systems with Applications 37 (2010) 7438-7448.

P. Moeinzadeh, A. Hajfathaliha, A Combined Fuzzy Decision Making Approach to Supply Chain Risk Assessment, World Academy of Science, Engineering and Technology International Journal of Mechanical, Aerospace, Industrial, Mechatronic and Manufacturing Engineering Vol:3, No:12, 2009. 